Lead Editorial

\title{
Re-framing continuity of care for this century
}

I Philibert, D C Leach

\section{Improvements are needed in teaching "hand-offs" to prevent communication failure between healthcare professionals}

I is widely accepted that "continuity of care" is vital to its quality and safety. The traditional approach to achieving this in the inpatient setting has been to minimize transfers among providers to reduce interruptions in the care process. In recent years the effort to limit duty hours for resident physicians (junior doctors) in the US, UK, and EU has highlighted the fact that continuity of care in teaching hospitals cannot depend on trainees working beyond limits that are advisable from a performance and safety perspective. Changing practice in teaching settings and a general movement toward shift and team based approaches to patient care have thrust into prominence the patient "hand-off" (also referred to as "handover," "sign-out," or "sign-over") as the process that enables multiple physicians collectively to ensure continuity and currency of information and care.

Hand-offs occur at many places in the care process. In teaching hospitals their frequency has increased since the imposition of limits on resident (junior doctor) hours, in large part due to the use of duty shifts and "short-call" and "cross-coverage" models in which responsibility for patients is transferred several times during the traditional 24 hour call period. Duty hour limits also appear to affect the hand-off in other ways, such as reducing the time available for this critical aspect of care.

\section{IMPORTANCE AND VULNERABILITY OF THE HAND-OFF}

How well a patient hand-off is made affects decision making and the subsequent quality of care. The article by Arora et al in this issue of QSHC highlights omitted information and communication failures as sources of uncertainly, inefficiency, and errors in patient care decisions. ${ }^{1}$ Their work, and a growing body of research on this topic, eloquently make the case for the handoff as an important and vulnerable point in the care process. Vulnerability results from the fact that errors or omissions in the information communicated through the hand-off often become "fact" for the next person or team using the information. $^{2}$ An example is the wrong side surgery that amputated the healthy leg of a patient because the hand-off between two surgical nurses did not correct an error by a unit clerk who had recorded the wrong leg for amputation. ${ }^{3}$ Conceptually, the hand-off is an additive task in which the performance of the incoming and outgoing physicians contributes cumulatively to the accuracy and completeness of the information exchange. Its fluid and loosely structured character, and the dynamic nature of a patient's condition, can result in information becoming lost or distorted or in its misinterpretation by the incoming physician. Consequences can include failure to identify patients whose condition is becoming critical, inefficient allocation of care resources to non-critical patients, duplication of services, and deviation from a previously established plan of care. The US accrediting body for hospitals has implicated communication failures in $60 \%$ of sentinel events reported to the organization and has added the hand-off to its patient safety goals for 2006, emphasizing the need for "a standardized approach to hand-off communications, including an opportunity to ask and respond to questions". ${ }^{4}$

\section{STUDY AND TEACHING OF THE HAND-OFF: THREE CONCEPTUAL SCHOOLS}

Despite its growing importance and potential vulnerability, the process for handing off patients is not currently taught in medical school or residency, and learning largely occurs informally at the bedside. A study of residents' suggestions for ways to reduce sources of healthcare error called the hand-off "remarkably haphazard", commenting that there is "no system of organized interaction" among participants. ${ }^{5}$ One reason may be the lack of a clear understanding of the process involved in a hand-off, and the advantages and possible drawbacks of different approaches. Other industries have given thought to the transfer of information and responsibility among professionals or teams. Patterson et al identified 21 strategies used in end of shift transfers in a number of industries that require accurate information transfer, including space shuttle mission control, power plants, and railroad and ambulance dispatch services. ${ }^{6}$ They proposed that many of these strategies are applicable to the patient hand-off, including providing the incoming physician with a summary of care plan changes, contingency plans and a list of tasks to be completed during the next duty period, and the transfer of responsibility for patients to the incoming physician in a clear and non-ambiguous fashion.

As the medical profession conducts research on the patient hand-off, three conceptual schools have emerged. All seek to remedy the perceived vulnerabilities of the hand-off, but different interpretations about causation lead to different approaches to enhance the integrity of the information transfer. The first school declares that its verbal format makes the hand-off vulnerable and suggests that information presented in a clear and consistent fashion using a paper based or computerized data form can counteract this. An example is the SBAR (Situation-BackgroundAssessment-Recommendation) approach which is used in a growing number of US hospitals through a cooperative arrangement that provides the SBAR tool at no charge. ${ }^{7}$ At present, a few institutions use an electronic sign-out form that is linked to the electronic medical record or patient order entry system which feeds it relevant data. Research related to this conceptual school of the hand-off frequency applies a standardized data set for the hand-off, finding that this reduces adverse outcomes and participant perceptions of "inadequate sign-out". ${ }^{9}$.

The second school believes that the loosely structured interactive nature of the hand-off has inherent strengths by allowing "real time recoding and synthesis". ${ }^{10}$ Brandwijk et al observed that verbal hand-offs in ICUs (1) include no more information than is needed; (2) are relevant to the context in which it is presented; (3) avoid ambiguity; and (4) provide accurate information. ${ }^{11}$ Research related to this model is often ethnographically based, and focuses on the attributes and tacit rules of communication and interpersonal variables such as trust, and how they affect the information transfer.

A third emerging conceptual school for the end of shift transfer has only been used in other industries, but its approach is congruent with a more explicit focus on systems that enhance 
patient safety by facilitating error detection and recovery. This school views the hand-off as an opportunity to reassess the information and practices from the prior period, with the incoming and outgoing team collaborating to detect errors and discrepancies. An example is in-flight management for NASA's space shuttle, which relies on verbal hand-offs to transfer control at the end of each ground team's shift. These transfers explicitly seek to identify and correct potential errors in the outgoing team's assessment of the status of the shuttle, with eight of 75 questions routinely asked serving solely to identify errors in the information used in flight management. ${ }^{12}$

Adding to the diversity of the approaches to studying the hand-off, there may also be conceptual differences about the role of the hand-off in the ongoing management of patients. Other terms for the hand-off include "signouts", "sign-overs", and "hand-overs". There is an emergent understanding that underlying the different terms are differences in the approaches used to manage care over the 24 hour day (I Philibert, unpublished data, 2005). "Sign-out" and "sign-over" are used in settings where a "day" provider or team transfers care to an evening or night shift. Common patterns include shortcall or night float. The underlying concept is that patients are moved from an active period of therapeutic management to a "holding phase" until the return of their regular provider. The physician accepting the sign-out has a mandate to deal with emergencies, but planning and execution of care are largely suspended. In contrast, underlying the terms "hand-off" and "handover" is a concept of 24 hour, 7 day continuous management of the patient, with the physician accepting a "handoff" fully empowered to manage all aspects of patient care. A common setting where this is used is the intensive care unit where management of patients cannot be put on hold. The distinction between "hand-off" and "sign-out" has carried over into studies of information transfers under shortcall and cross-coverage schedules. ${ }^{8}$ It has also been incorporated into the emerging curricula used to improve teaching of the hand-off, with some including explicit instructions for how (and when not) to sign out diagnostic studies and the reporting of the results in a "short-call" situation. ${ }^{13}$

\section{FACILITATING LEARNING AND IMPROVEMENT IN THE HAND-OFF}

The patient hand-off has emerged as an important element in the patient care process, worthy of the focus of research- ers and medical educators. At the same time, different perceptions of the role of the hand-off in the ongoing management of care, and differences in the theories about what constitute important vulnerabilities, have led to diversity in the approaches for how it is studied and taught. Transcending the particular school of research and teaching of the hand-off could assist in overcoming potential trade-offs between approaches. For example, in selecting between a traditional verbal hand-off and the use of an electronic supported data format, a disadvantage of electronically linked systems is the inability to tailor data to the critical data elements for the given patient. A more serious drawback is not part of the electronic system, but can result when it is used to replace the interactive verbal communication during the hand-off, with studies showing that electronic systems cannot substitute for successful face-toface communication. ${ }^{14}$ This finding is important as teaching institutions are looking for time efficient approaches to transfer care under the limits imposed on the hours of residents and, in some nations, all practitioners. It is echoed in the comments by the interns in the study by Arora et al that the hand-off should occur face-to-face, and in its summary of problems. ${ }^{1}$

The discussion about the benefits and vulnerabilities of a verbal, dynamic, interactive hand-off versus an approach supported by consistent data mirrors the larger debate in the medical profession about the circumstances in which medical professionals should use judgment and when, in the consensus of experts, discretionary judgment should be taken out of the equation. Given that the information underlying the patient hand-off is characterized by uncertainty and ambiguity, this debate does not have an easy resolution when applied to the hand-off. Practical wisdom in a highly regimented discipline such as aviation tells us that, when standard operating procedures do not work, conversations to explore effective strategies may be beneficial (W Rutherford, personal communication, 2005).

This wisdom could be applied to medicine, with curricula related to the hand-off explicitly including instruction on when and how to use discretionary judgment and transcend the information in regimented data sets designed to support the hand-off. Teaching the hand-off may also benefit from a more explicit teaching of the expectations and values underlying its purpose in the management of care. This repeats the question raised by Gardner and colleagues $^{15}$ in their examination of professional development in two disciplines:
"Why is it that experts primarily teach techniques to young professionals while ignoring the values that have sustained the quests of so many creative geniuses?"

Researchers and experts in the health professions and in other industries are accumulating knowledge related to the transfer of information and responsibility among practitioners and teams. At present, learning across these efforts may be impeded by the lack of ongoing discourse and sharing between the various approaches to studying the hand-off and the different theories about the sources of its vulnerability. Findings from the three schools of study of the hand-off and the knowledge from other industries applied collectively will contribute to our understanding of this important process and to improvements in teaching and practice. At present, the diverse communities doing this work do not communicate to any significant extent. What may be helpful is a forum in which researchers and educators representing the different schools can share findings and engage in dialogue to advance research and education, combining the best of all approaches. This could contribute to more rapid accumulation and dissemination of new knowledge, and more timely development of approaches for teaching the hand-off. The ultimate benefits would greatly exceed the time and costs that would be devoted to such an endeavor. In addition to the important benefits for patient safety and reduction of anguish for patients and their families as their care is more closely and explicitly coordinated, there could be reductions in cost and length of stay.

Qual Saf Health Care 2005;14:394-396. doi: 10.1136/qshc.2005.016170

\section{Authors' affiliations}

I Philibert, D C Leach, Accreditation Council for Graduate Medical Education, Chicago, IL, USA

I Philibert, Department of Health Management and Policy, College of Public Health, University of lowa, USA

Correspondence to: Ms I Philibert, Accreditation Council for Graduate Medical Education, 515 North State Street, Suite 2000, Chicago, IL 60610, USA; iphilibert@acgme.org

IP and DL are employed by the Accreditation Council for Graduate Medical Education, the organization that develops and enforces educational standards for more than 8000 accredited residency education programs. IP is completing doctoral dissertation research on the patient hand-off in the Department of Health Management and Policy, College of Public Health, University of lowa. 


\section{REFERENCES}

1 Arora V, Johnson J, Lovinger D, et al. Communication failures in patient sign-out and suggestions for improvement: a critical incident analysis. Qual Saf Health Care 2005; 14:401-7.

2 Reason JT, Carthey J, de Leval MR. Diagnosing "vulnerable system syndrome": an essential prerequisite to effective risk management. Qual Saf Health Care 2001;10(Suppl II):ii21-5.

3 Cook RI, Woods DD, Miller C. A tale of two stories: contrasting views on patient safety. Chicago, IL: National Patient Safety Foundation, 1998, Available at: http://www.npsf.org/exec/ toc.html (accessed 15 September 2005).

4 Joint Commission on the Accreditation of Healthcare Organizations. Sentinel event statistics. Available at: http://www.jcaho.org/ accredited+organizations/sentinel+event/ sentinel+event_statistics.thm (accessed 15 September 2005)
5 Volpp GM, Grande D. Residents' suggestions for reducing errors in teaching hospitals. NEngl J Med 2003;348:851-5.

6 Patterson ES, Roth EM Woods DD, et al. Handoff strategies in settings with high consequences for failure: lessons for health care operations. Int J Qual Health Care 2004;16:125-32.

7 Institute for Healthcare Improvement. Patient safety tools: SBAR technique for communication. Boston: Institute for Healthcare Improvement 2005. Available at: http://www.ihi.org/IHI/ Topics/PatientSafety/SafetyGeneral/Tools/ SBARTechniqueforCommunicationASituationalBriefingModel.htm (accessed 15 September 2005).

8 Petersen LA, Orav EJ, Teich JM, et al. Using a computerized sign-out program to improve continuity of inpatient care and prevent adverse events. It Comm J Qual Improv 1998;24:77-87.

9 Lee LH, Levine JA, Schultz HJ. Utility of a standardized sign-out card for new medical interns. J Gen Intern Med 1996;11:753-5.
10 Tushman M. Impacts of perceived environmental variability on patterns of work related communication. Acad Mgmt J 1979;223:482-500.

11 Brandwiik N, Nemeth C, O'Connor $M$, et al. Distributed cognition: ICU hand-offs conform to Grice's maxims. 2003. Available at: http://www. ctlab.org/documents/SCCMPoster 1.27.03.pdf.

12 Patterson ES, Woods DD. Shift changes, updates, and the on-call architecture in Space Shuttle Mission Control. Supported Cooperative Work 2001; 10:317-46.

13 Mangrulkar RS. A seminar to improve the handover of patients. Ann Arbor, Ml: University of Michigan Health System, Department of Medicine, 2004

14 Ash JS, Berg M, Coiera E. Some unintended consequences of information technology in health care: the nature of patient care information system-related errors. J Am Med Inform Assoc 2004;11:121-4

15 Gardner H, Csikszentmihalyi M, Damon W. Good work: when excellence and ethics meet. New York: Basic Books, 2001

\section{Clinical Evidence-Call for contributors}

Clinical Evidence is a regularly updated evidence-based journal available worldwide both as a paper version and on the internet. Clinical Evidence needs to recruit a number of new contributors. Contributors are healthcare professionals or epidemiologists with experience in evidence-based medicine and the ability to write in a concise and structured way.

Areas for which we are currently seeking contributors:

- Pregnancy and childbirth

- Endocrine disorders

- Palliative care

- Tropical diseases

We are also looking for contributors for existing topics. For full details on what these topics are please visit www.clinicalevidence.com/ceweb/contribute/index.jsp

However, we are always looking for others, so do not let this list discourage you.

Being a contributor involves:

- Selecting from a validated, screened search (performed by in-house Information Specialists) epidemiologically sound studies for inclusion.

- Documenting your decisions about which studies to include on an inclusion and exclusion form, which we keep on file.

- Writing the text to a highly structured template (about 1500-3000 words), using evidence from the final studies chosen, within 8-10 weeks of receiving the literature search.

- Working with Clinical Evidence editors to ensure that the final text meets epidemiological and style standards.

- Updating the text every 12 months using any new, sound evidence that becomes available. The Clinical Evidence in-house team will conduct the searches for contributors; your task is simply to filter out high quality studies and incorporate them in the existing text.

If you would like to become a contributor for Clinical Evidence or require more information about what this involves please send your contact details and a copy of your CV, clearly stating the clinical area you are interested in, to CECommissioning@bmigroup.com.

\section{Call for peer reviewers}

Clinical Evidence also needs to recruit a number of new peer reviewers specifically with an interest in the clinical areas stated above, and also others related to general practice. Peer reviewers are healthcare professionals or epidemiologists with experience in evidence-based medicine. As a peer reviewer you would be asked for your views on the clinical relevance, validity, and accessibility of specific topics within the journal, and their usefulness to the intended audience (international generalists and healthcare professionals, possibly with limited statistical knowledge). Topics are usually 1500-3000 words in length and we would ask you to review between 2-5 topics per year. The peer review process takes place throughout the year, and out turnaround time for each review is ideally 10-14 days.

If you are interested in becoming a peer reviewer for Clinical Evidence, please complete the peer review questionnaire at www.clinicalevidence.com/ceweb/contribute/peerreviewer.jsp 